\title{
Paralleled DC Boost Converters with Feedback Control using PSO Optimization Technique for Photovoltaic Module Application
}

\author{
Abhimanyu KumarYadav \\ ${ }^{1}$ School OfSolar EnergyPandit \\ Deendayal Petroleum Univ. \\ Gandhinagar,Gujarat.
}

\author{
Vishal Mehra ${ }^{2}$ \\ Abhijit Ray ${ }^{1}$ \\ ${ }^{2}$ School Of Technology Pandit \\ Deendayal Petroleum Univ.
}

\author{
Anil Markana ${ }^{2}$, \\ Makarand Lokhande ${ }^{3}$ \\ ${ }^{3}$ E.E.Dept.,SVNIT,Surat
}

\begin{abstract}
In this paper a novel method of controller design for boost type dc-dc converter is proposed. DC/DC converters are widely used in photovoltaic generating systems as an interface between the photovoltaic panel and the load. Therefore, a better possible control technique is required in order to control the variation in output voltage of DC/DC converter due to the variation occurring in the external dynamics input parameters such as radiation, temperature and internal impedance of the photovoltaic (PV) module. In this paper, two paralleled DC/DC converter with a closed loop PWM based control is simulated to obtain constant output voltage. The optimal values of feedback PID controller are obtained using Particle Swarm Optimization Algorithm (PSOA). Extensive simulation result is found out with linear controller parameters and the same are presented here. Here comparison of the output of the PSOA based design and design of PID controller with transient performance specification (T-PID) for underdamped system is done. The PSO based tuning of PID controller is much better as determined by the simulation results.
\end{abstract}

\section{General Terms}

Transient performance specification, Particle Swarm Optimization Algorithm.

\section{Keywords}

DC/DC Converter, PSO-PID, Pulse width modulation, solar energy.

\section{INTRODUCTION}

Solar energy, which is available free of cost and is abundant for long hours during daytime and with high intensity throughout the year, especially in Gujarat, India. To capture these abundant, free solar energy very efficiently, various efforts are being deployed in the fields of material science of photovoltaic, power electronics and control automation all over the globe. The solar energy market is experiencing a remarkable rapid growth since last decade, in the areas of widespread use from solar portable devices; electric vehicles (EV) to standalone system and up to the interactive PV connected grid system. A latest lesson learned from Germany is of $21 \mathrm{PV}$ systems in operation for 10 years, exposed that inverters contributed for $63 \%$ of failures, PV modules $15 \%$ and other components $23 \%$, with a failure occurring, on an average, every 4.5 years [1]. In order to reduce the high failure rates of PV balance of system (BOS) and directly the cost of these power system, research uses the mathematical models for the analysis of developed system performances. One of the important systems of BOS is the DC/DC converter which may get transformed into DC transformer for the DC micro-grid application in future. The paralleling of switching converters based on power supply contributes many advantages when compared with a single high power centralized power supply [2]. Utilization of the DC low voltage opens new possibilities for network distribution development and low voltage residential application. A DC Micro-grid can reduce AC to DC conversion losses from an average of $32 \%$ to $10 \%[3,4]$.

The DC/DC converters are nonlinear dynamic systems. The primary reasons for the non-linearity are due to high frequency switching, power devices like MOSFETs, diodes and passive components such as inductors and capacitors. Therefore, there is a need for an optimal control technique for these DC/DC converters which can deal with their intrinsic nonlinearity and wide variations in the input voltage and load variations ensuring stability in any operating condition while taking care of in obtaining the fast transient response.

In [5] this review paper, it is concluded that the best type of converter among the non-isolated DC/DC converter for PV system is the buck-boost DC/DC converter. To ensure PV module operation point always at MPP, DC/DC converters are used [6]. In another paper a complete control system that uses two DC/DC converters to control the operating power of the electrolyser and the fuel cell is presented. The simulation results of PID controller and a fuzzy logic controller to manage the flow of energy in the system were almost same and since the PI controller is simpler to implement, it was retained as the best option[7].In [8] the conventional PID controlled DC/DC converter is discussed and it is proved that by using BFOA-PID the peak overshoot of the response is very much reduced and its settling time is very less, robustness in its stability is also improved when subjected to external disturbances. A non-isolated boost converter is connected with the PV module at its input side and at its output a load is connected which is to be driven. The results published in [9] indicate that the performance of the fuzzy controller is superior to that of the linear PID and PI controllers. The fuzzy controller is able to achieve more stable steady-state response, faster transient response, and highly robust under different operating points. In [10] this paper, a novel genetic algorithm based smart-PID controller for optimal control of DC-DC boost converter used as voltage controller in PV systems. It maximizes the stable operating range by using genetic algorithms (GA) to tune the PID parameters at various loading conditions.

The digital simulation results presented in [11] concluded that the enhanced PSO algorithm has stable convergence characteristic and good computation ability, and it is an effective method for optimal tuning of PID gains. In order to improve the performance of the controller, a modified PSO method is proposed and experiments confirm the method can improve the performance of PID controller dramatically [12]. In this paper boost converter is used to step up the low variable voltage from the PV module and provide the high quality, regulated DC voltage. Section 2 describes about the design of DC converter and in section 3, the PID controller 
optimization using two different methods is discussed. In section 4 two similar closed loop DC-DC boost converters are paralleled and simulated results are discussed.

\section{DESIGN OF BOOST CONVERTER:}

In this section a conventional non-isolated DC/DC boost converter operating in continuous current mode is discussed. The MOSFET switch and diode is assumed to be ideal and the passive electronics elements such as capacitor and inductor are ideal with no parasitic resistances. The simplified form of DC/DC boost converter is shown in Fig 1.

In [13] a boost converter operating in continuous current mode which is able to draw maximum power from the PV system for a given irradiation level by adjusting the duty cycle of the converter is discussed.

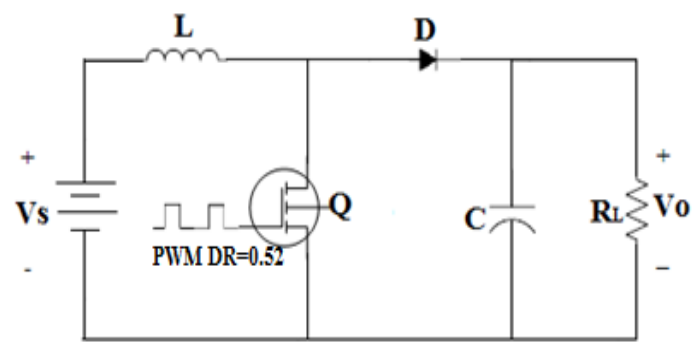

Fig 1: Conventional PWM Switching Boost DC/DC Converter

The ideal dynamics of the boost converter are derived by the state space averaging method. The boost converter, step up the input voltage to a voltage equal to input and higher value. The relationship between the input voltage (Vs) and the output voltage (Vo) is given [14] as:

$$
\mathrm{Mv}=\frac{\mathrm{V}_{\mathrm{o}}}{\mathrm{V}_{\mathrm{s}}}=\frac{1}{1-\mathrm{D}}
$$

Where, $D=\frac{T_{\text {on }}}{T_{s}}$, is the duty ratio, $T s$ is the switching period, Ton is conducting time of the switch, $\mathrm{R}_{\mathrm{L}}$, is the load resistance and $f s$ is the switching frequency. The mode of operation of the boost converter in CCM mode is decided by the positive values of inductor current. The boundary condition between CCM and DCM of the Boost converter is dependent on the critical value of the inductor $L$ and is given in [14] as:

$$
\mathrm{L}=\frac{T_{S} V_{o}}{I_{o B}} D(1-D)^{2}
$$

Where $I_{O B}$ is the average value of the output current and values of $\mathrm{D}$ and $\mathrm{V}_{\mathrm{o}}$ is constant. The converter to operate in CCM mode should have larger value then the critical inductor value. This inductor value determines the magnitude of ripple current in the output capacitor as well as the load current. The value of the components used in the boost converter are $\mathrm{L}$ is $18 \mathrm{mH}, \mathrm{C}$ is $980 \mu \mathrm{F}$, load resistor $\mathrm{R}_{\mathrm{L}}$ value is $26 \Omega$, switching frequency $100 \mathrm{kHz}$ and the duty ratio is 0.52 .The transfer function of the boost converter is given by equation 3

$$
\begin{aligned}
\text { T. F } & =\frac{\mathrm{V}_{\mathrm{O}}}{\mathrm{V}_{\mathrm{in}}}=\frac{\left(\frac{1}{\mathrm{LCR_{ \textrm {L } }}}\right)}{\mathrm{S}^{2}+\frac{\mathrm{S}}{\mathrm{LCR}}+\frac{1}{\mathrm{LC}}} \\
& =\frac{2.18 * 10^{3}}{\mathrm{~S}^{2}+2.18 * 10^{3} \mathrm{~S}+5.67 * 10^{4}}
\end{aligned}
$$

\section{DESIGN OF PID CONTROLLER:}

The performance of a closed loop converter is greatly influenced by controller parameters. The controller ensures stable operation of the converter. In practice, PID is the most common used controller for the control of DC/DC converters due to their adoption in all other closed loop systems $[15,16]$. The PID controller provides control signal which is relative to the error between the reference signal and the actual output, to the integral of the error and to the derivative of the error. The general equation of control signal for a PID controller is as follows:

$u(t)=K_{p}\left[e(t)+\frac{1}{T_{i}} \int_{0}^{t} e(\tau) d \tau+T_{d} \frac{d}{d t} e(t)\right](4)$

Where $u(t)$ and $e(t)$ denote the control and error signals, $K_{p}$, $\mathrm{T}_{\mathrm{i}}$ and $\mathrm{T}_{\mathrm{d}}$ are the parameters to be tuned. The transfer function is given as

$K(s)=K_{p}\left(1+\frac{1}{T_{i} s}+T_{d} s\right)$

Two different algorithms are used for tuning the gain parameters of the PID controller and their results are compared. The particle swarm optimization algorithm (PSO) for PID tuning and tuning design of PID as proposed in [17] is used to tune the PID controller and their results are compared. The objectives of optimization problem is to minimizing rise time, settling time, ripple and steady state error of the output voltage of the boost converter corresponding to step changes in input voltage and load. The optimization process yields values of $\mathrm{K}_{\mathrm{p}}, \mathrm{K}_{\mathrm{i}}, \mathrm{K}_{\mathrm{d}}$ that are optimal for different output voltage ranges. The values of $K_{p}, K_{i}$ and $K_{d}$ determine the compensator design, performance and stability.

A large proportional gain $\left(\mathrm{K}_{\mathrm{p}}\right)$ results in a large change in the output of the PID compensator for a small change in error. The integral constant $\left(\mathrm{K}_{\mathrm{i}}\right)$ decreases the settling time and helps in eliminating the steady state error and the derivative term $\left(\mathrm{K}_{\mathrm{d}}\right)$ slows the rate of change of the PID compensator output. A PID controller is basically known to be a form of phase lead-lag compensator having a pole located at origin and the other at infinity [18]. 


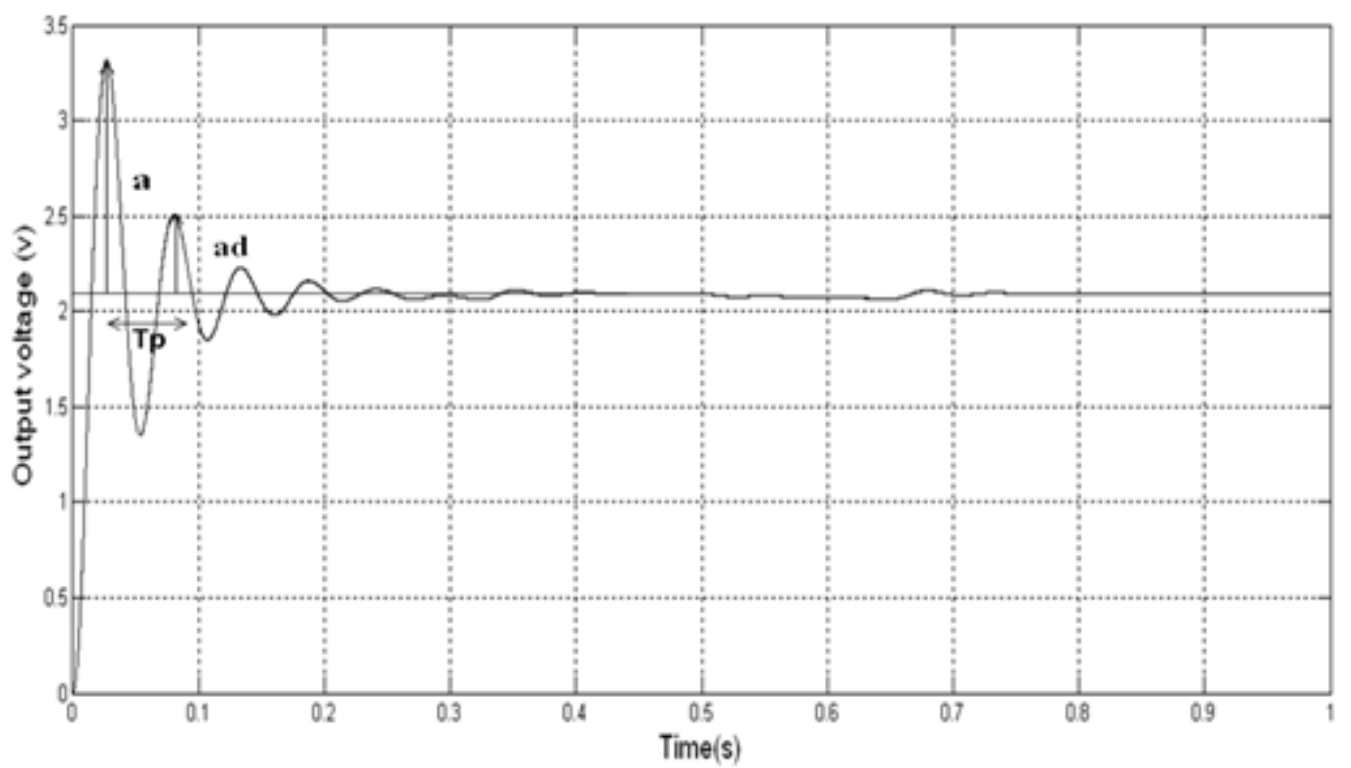

Fig.2.Step response of an under-damped second-order DC boost converter

\subsection{Transient specified tuned PID controller (T-PID)}

The step response of an under-damped second-order design of the DC boost converter is shown in Fig. 2 where a, Tp and ad are 3.3,0.35, 0.05 respectively .System with under-damped step response may be approximated by a second-order system with transfer function [19].

$$
\mathrm{T}(\mathrm{s})=\frac{\mathrm{K} \omega_{\mathrm{n}}^{2}}{\mathrm{~s}^{2}+2 \zeta \omega_{\mathrm{n}}^{2}+\omega_{\mathrm{n}}^{2}}
$$

Where $\zeta$ is in range of $0<\zeta<1$ for an ideal second-order system with transfer function (6). The step input response with amplitude $\mathrm{M}$ is given as in [24],

$S(t)=$

$J M\left[1 \frac{1}{\sqrt{1-\zeta^{2}}} e^{-\zeta \omega_{n} t} \sin \left(\omega_{n} \sqrt{1-\zeta^{2} t}+\right.\right.$

$\phi)]$

toward suitably tuning the controller gain, where $\phi=$ $\arccos (\zeta)$. The dc-gain $J$, the natural frequency $\omega_{n}$ and the damping coefficient $\zeta$ is determined as computed in [19] which are as follows:

$$
\zeta=\frac{1}{\sqrt{1+\left(\frac{2 \pi}{\ln d}\right)^{2}}}, \omega_{n}=\frac{2 \pi}{T_{p} \sqrt{1-\zeta^{2}}}
$$

The PID controller for the under damped second-order system is presented by rewriting the transfer function (5) as

$$
K(s)=\frac{K_{p} T_{d}}{s}\left(s^{2}+\frac{1}{T_{d}} s+\frac{1}{T_{d} T_{i}}\right)
$$

Since the system is of second order, it has a pair of complex poles as $-\zeta \omega_{n} \pm j \omega_{n} \sqrt{1-\zeta^{2}}$. The suitable choice for the controller zeros should be such that the numerator polynomial of $\mathrm{K}(\mathrm{s})$ and denominator polynomial of $\mathrm{T}(\mathrm{s})$ eliminate each other [17]. To obtain this condition, $T_{i}$ and $T_{d}$ must fulfill the equations as follows,

$$
T_{d}=\frac{1}{2 \zeta \omega_{n}}, \text { and } T_{i}=\frac{2 \zeta}{\omega_{n}} .
$$

The computed values of $K_{P}, T_{d}$ and $T_{i}$ for the PID controlled close loop boost converter is given in table 2 .

\subsection{PID gain optimization using PSO algorithm (PSO-PID)}

The gain of PID controller used is determined by particle swarm optimization (PSO) algorithm [20]. PSO is a multi-agent parallel search technique where say $\mathrm{n}$ flying entities fly through the multidimensional search space as the algorithm progresses through discrete time steps i.e. $t=0,1,2$, ..., while keeping the population size $\mathrm{m}$ constant. In the standard PSO algorithm, each particle's current position Xi (t) $=[\mathrm{Xi}, 1(\mathrm{t}), \mathrm{Xi}, 2(\mathrm{t}), . . \mathrm{Xi}, \mathrm{n}(\mathrm{t})]$ and its current velocity $\mathrm{VI}(\mathrm{t})=$ [VI, $1(\mathrm{t}), \mathrm{VI}, 2(\mathrm{t}) \ldots \mathrm{VI}, \mathrm{n}(\mathrm{t})]$, where $\mathrm{i}=1,2, \ldots \mathrm{m}$ is considered and accordingly its personal best position $\operatorname{Pi}(\mathrm{t})$ and global best position $\mathrm{G}(\mathrm{t})$ is found with respect to the origin of search space. Here one position is declared better than another if the former gives a lower value of the objective function than the latter. This function is called the fitness function. Each particle's initial position vector component $\mathrm{Xi}, \mathrm{j}(0)$ is picked randomly from a predetermined search range $[\mathrm{XLj}, \mathrm{XUj}]$ and its velocity components is initialized by choosing at random from interval [-Vjmax, Vjmax]. The initial settings for Pi (t) and $\mathrm{G}(\mathrm{t})$ is given below

$$
P_{i}(t)=X_{i}(0), G(0)=X_{k}(0)
$$

such that $f\left(X_{k}(0)\right) \leq f\left(X_{i}(0)\right) \forall i$,

where $\forall i$, represent for all values of i [20]. The iterative optimization process for the initialized particle begins and the position and velocities of all the particles are updated by the following recursive equations (9), (10). Given equations are for $\mathrm{jth}$ dimension of the position and velocity of the ith particle.

$$
\begin{gathered}
\quad \mathrm{V}_{\text {id }}(\mathrm{t}+1) \\
=\omega \mathrm{V}_{\text {id }}(\mathrm{t})+\mathrm{C}_{1} \Phi_{1}\left(\mathrm{P}_{\mathrm{id}}(\mathrm{t})-\mathrm{X}_{\mathrm{id}}(\mathrm{t})\right) \\
+\mathrm{C}_{2} \Phi_{2}\left(\mathrm{P}_{\text {gd }}(\mathrm{t}) \mathrm{X}_{\text {id }}(\mathrm{t})\right) \\
\mathrm{X}_{\mathrm{id}}(\mathrm{t}+1)=\mathrm{X}_{\mathrm{id}}(\mathrm{t})+\mathrm{V}_{\mathrm{id}}(\mathrm{t} 1)
\end{gathered}
$$

Where $\omega$ : Time-decreasing inertial weight factor designed by Shi and Eberhurt [20]. $\mathrm{C}_{1}=2.4, \mathrm{C}_{2}=1.6$. Two constant 
multipliers called self confidence and swarm confidence respectively, $\Phi_{1}, \Phi_{2}$. Two uniformly distributed random number. The iteration is fixed for certain number of time steps or until the fitness of the best particle at a certain time step is better than a predefined value is obtained. The fittest vector of the final population upon termination of the algorithm is taken as the possible solution of the problem.PSO is more efficient in maintaining the diversity of the swarm, since all the particles use the information related to the most successful particle in order to improve themselves, whereas in Genetic algorithm, the worse solutions are discarded and only the new ones are saved [21]. The PSO parameter used in this application is given in table 1 .

Table1. PSO parameter and value:

\begin{tabular}{|l|l|}
\hline PSO Parameter & Value \\
\hline Population size & 20 \\
\hline $\mathrm{V}_{\min }$ & -3 \\
\hline $\mathrm{V}_{\max }$ & 3 \\
\hline $\mathrm{C}_{1}, \mathrm{C}_{2}$ & $2.4,1.6$ \\
\hline No. of Iterations & 40 \\
\hline
\end{tabular}

The parameters obtained from the under-damped second order single boost converter using PID controller with transient performance specification (T-PID) and PSO algorithm is tabulated in table 2 .

Table2. Tuning parameter of PID controller

\begin{tabular}{|l|l|l|l|}
\hline PID Parameters & $\mathbf{K}_{\mathbf{p}}$ & $\mathbf{K}_{\mathbf{i}}$ & $\mathbf{K}_{\mathbf{d}}$ \\
\hline $\begin{array}{l}\text { PID controller with } \\
\text { transient performance } \\
\text { specification }\end{array}$ & 0.092 & 0.00544 & 0.05 \\
\hline PSO-PID & 114.32 & 11.56 & 0 \\
\hline
\end{tabular}

The voltage overshoot is less than a percent, it is tracking 48 volt and settling time is less about $0.02 \mathrm{msec}$ and steady state error is zero in case of the PID controller tuned by the PSO algorithm. The simulated result of the single boost converter is shown in Fig3.

As the control of inductor is not considered, therefore we can see that there is overshooting of current is occurring in both the tuning method and as a result there is fluctuation in the output power. As this result determines that tuning of PID controller by PSO algorithm is more suitable for output voltage control of the DC converter, which is implemented in our proposed work in section IV. Here two converters of same kind are connected in parallel for harvesting of distributed renewable energy sources such as photovoltaic module. The objective of paralleling the DC boost converter is to increase the power density and make the DC system more reliable and redundant and the same is tried here to prove in the proposed work. The performance indices of the PID controller as discussed in [22] is tuned by the above mentioned method and the determined indices value are plotted in table 3 . Table 3 shows that the PID controller for the boost converter tuned by PSO method is more effective as compared to the PID controller with transient performance specification (T-PID) method.

Table3: Performance indices of PID controller

\begin{tabular}{|l|l|l|l|}
\hline $\begin{array}{l}\text { Performance } \\
\text { Index of PID }\end{array}$ & ISE & IAE & ITAE \\
\hline $\begin{array}{l}\text { PID controller v } \\
\text { transient } \\
\text { performance } \\
\text { specification }\end{array}$ & 24.78 & 1.008 & 0.02301 \\
\hline PSO-PID & 10.81 & 0.2854 & 0.00104 \\
\hline
\end{tabular}

The fitness function of PSO algorithm is defined

The fitness function of PSO algorithm is defined by 1/ISE, 1/IAE and 1/ITAE. The larger values of the fitness function suggest that the performance of the DC converter system response is better with the specified PID parameters in case of PSO applied technique.

Table 4 shows that the PID controller for the boost converter tuned by PSO method is more effective in terms of settling time and maximum overshoot voltage.

Table4: Performances evaluation of PID controller

\begin{tabular}{|l|l|l|}
\hline Parameters & $\begin{array}{l}\text { PID } \\
\text { controller } \\
\text { with transient } \\
\text { performance } \\
\text { specification }\end{array}$ & PSO-PID \\
\hline Settling time & $0.16 \mathrm{sec}$ & $0.00899 \mathrm{sec}$ \\
\hline $\begin{array}{l}\text { Maximum } \\
\text { overshoot } \\
\text { voltage }\end{array}$ & $21.28 \mathrm{~V}$ & $0.03 \mathrm{~V}$ \\
\hline $\begin{array}{l}\text { Steady state } \\
\text { error }\end{array}$ & $0.03 \mathrm{~V}$ & $0.03 \mathrm{~V}$ \\
\hline
\end{tabular}

\section{PROPOSED WORK:}

In the proposed type of configuration, each constituent nonisolated converter has its own voltage loop to regulate the output voltage. 


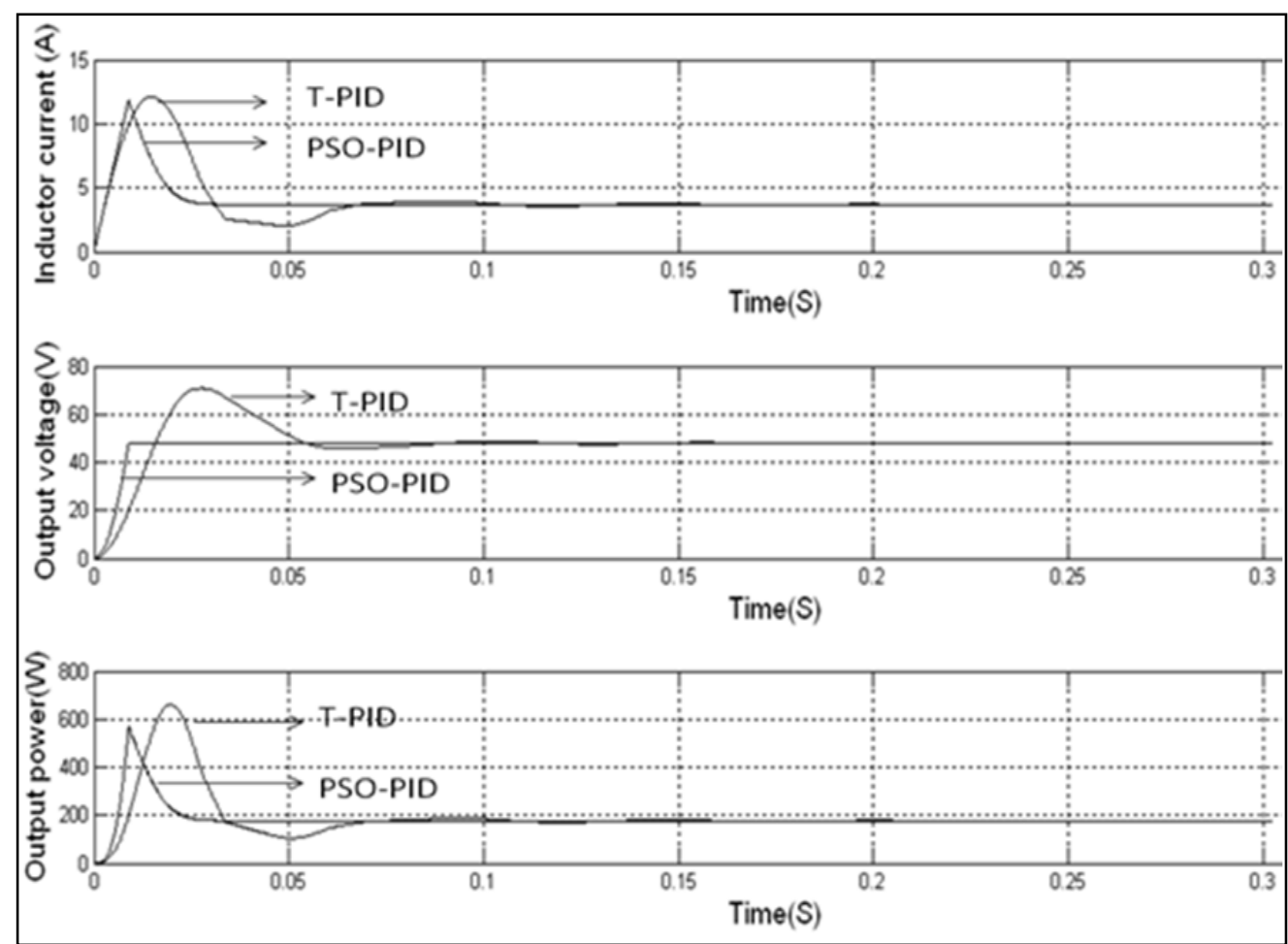

Fig.3.Tuning of PID controller of the single closed loop boost converter by PID controller with transient performance specification and PSO-PID method.

The need for parallel configuration of converters is to extract maximum power from the existing renewable sources without putting much stress on a particular converter.

The variable output voltage and current of the renewable sources are dependant parameters such as on irradiation and wind velocity etc. The objective of closed loop non-isolated DC converter is to regulate the unregulated output voltage and current of the renewable sources.

This is achieved using proper current and voltage sharing mechanism. The circuit diagram of the closed loop paralleled converter configuration is shown in Fig 4.
The output impedance of the jth closed loop converter is given [2] by

$$
\mathrm{Z}_{\mathrm{jth}}=\mathrm{Z}_{\mathrm{CLj}}+\mathrm{r}_{\text {conj }}
$$

where $\mathrm{Z}_{\mathrm{CLj}}$ is impedance of closed loop converter and $\mathrm{r}_{\text {conj }}$ is the connecting wire impedance and the steady-state currentsharing error is expressed as

$$
\Delta I=I_{1}-I_{2}
$$




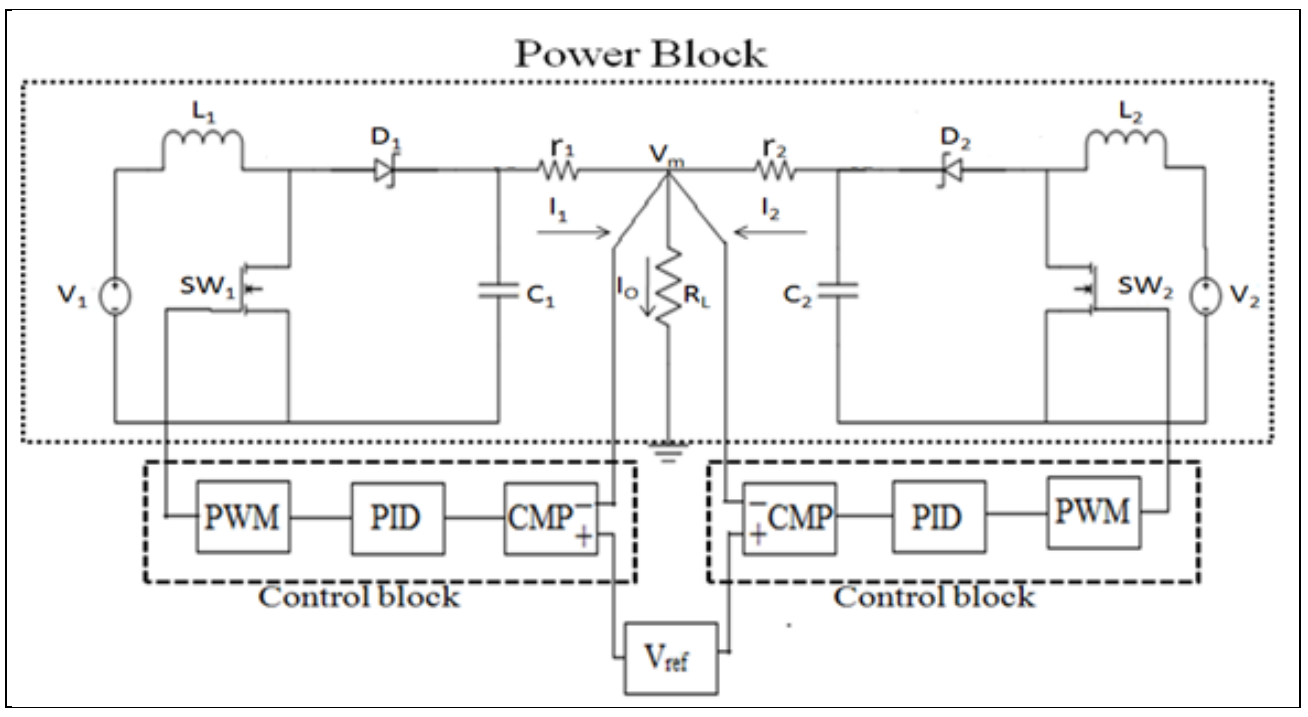

Fig.4. Paralleled voltage controlled boost converters

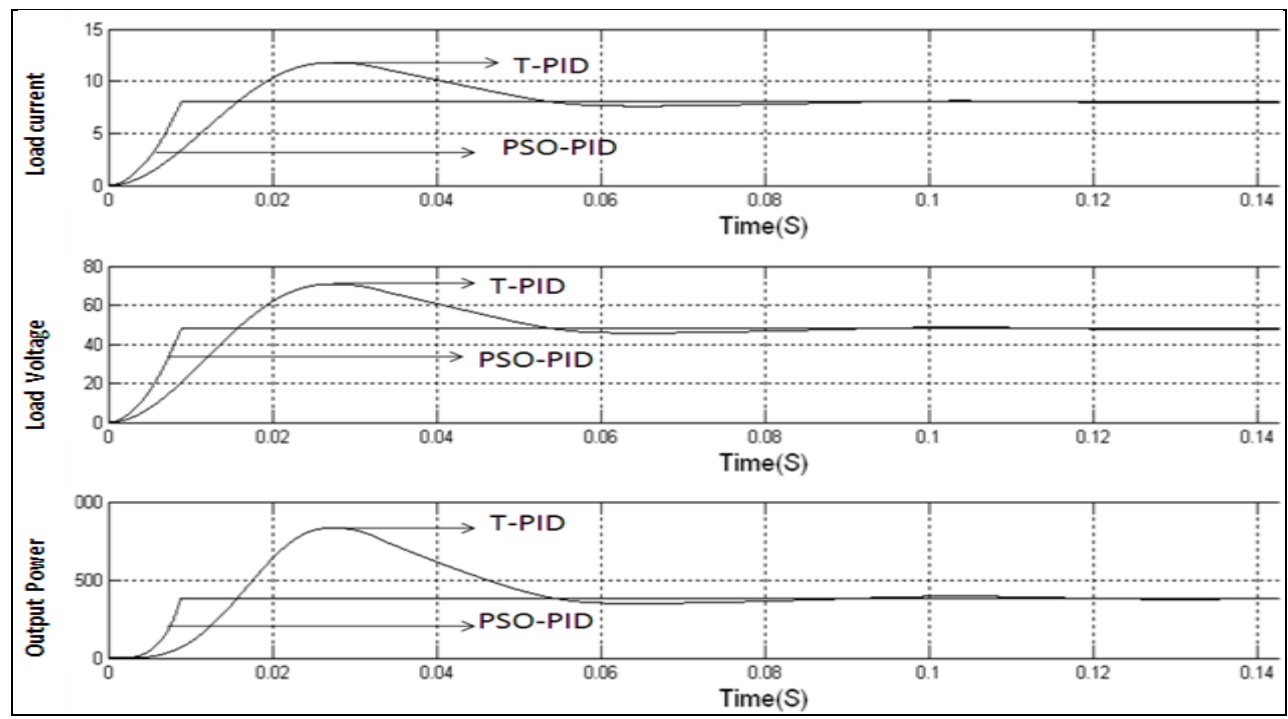

Fig 5. Tuning method comparison of PID controller between transient performance specification (T-PID) and PSO algorithm method for the paralleled closed loop boost converters.

This type of configuration can be used with photovoltaic modules as voltage source to regulate the voltage of a bus for DC micro-grid type applications. To accomplish this, here the output voltage is feedback to the comparator where it is compared with a reference voltage and the output is given to PID controller. The PID controller tries to maintain the constant voltage across the load. The gain value of the PID controller is found out using PSO technique and it is one of the best algorithms which provide accurate gain values. The input voltage for left boost converters is 24 volts and for right side converter is $20-24$ volt as there is variation in PV module is randomly given to find if there is any difference in output, but in this range no change in output voltage is seen. The output voltage across the load $6 \Omega$ is maintained constant at 48 volts and combined power available at load is 383.44 watt as both DC boost converter are connected in parallel as shown in Fig 5. It is observed in Fig5 that the overshoot, rise time and settling time is significantly less in case of PSO tuned PID controller when compared with the PID controller with transient performance specification (T-PID) based tuning. The same PSO tuned PID controller for closed loop parallel boost converters is used in [23] and the results obtained are appropriate for paralleling DC/DC converter located at some minimum distances with varying cable resistances.

\section{CONCLUSION}

The objective of enhancing the PID control for unstable processes is proposed in this paper. It is shown in simulation result that there is considerable improvement in the system transient characteristics in terms of peak amplitude, lesser rise time, peak overshoot, settling time and Performance index was also reduced in our proposed application. Results are more refined in modern evolutionary control tuning algorithms than conventional control tuning algorithm. The performance index for various error criterions for the proposed controller using PSO algorithm is proved to be less than the controller tuned by PID controller with transient performance specification (T-PID) method. Therefore, this 
method of tuning may be implemented in DC-fed paralleled DC converter systems for low voltage residential applications where tight regulation of voltage is required. The DC sources can be any distributed renewable energy sources like wind, solar photovoltaic and fuel cell etc. The proposed system can be deployed to distributed renewable energy sources in Low voltage (LV) DC micro-grid applications.

\section{FUTURE WORK}

The implementation of evolutionary PSO algorithm in advanced micro-controller for tuning of PID controller in closed loop parallel DC/DC converter may prove to be efficient in regulating the fluctuations of voltages in renewable energy sources. This system used for residential low power applications can prove to be quite useful in energy saving if interfaced with battery bank. The medium to low voltage (48V) DC applications for residential use will be more reliable and efficient in future. These medium to low voltage network can later be reconstructed which may results in formation medium range DC power micro-grids.

\section{ACKNOWLEDGEMENT}

The authors would like to thank Dr.Indrajit Mukhopadhyay, H.O.D of School of Solar Energy and Prof. Naresh Jotwani ,Former-Director, School of Solar Energy, for the constant motivations in this work

\section{REFERENCES}

[1]"PV Balance of systems conference Berlin, Germany," June 2011, http://www.PVinsider.com.

[2] Yuehui Huang and Chi K. Tse ,:"On the Basins of Attraction of Parallel Connected Buck Switching Converters,'IEEE,2006.

[3] Savage, P.N.; Robert, R.; Jamieson, S.P.:DC Microgrids: Benefits and Barriers; Yale School of Forestry \& Environmental Studies: New Haven, CT, USA, 2010.

[4]Jiang, W.; Fahimi, B. :'Multi-port power electric interface for renewable energy sources'. In Proceedings of the 24th Annual IEEE Applied Power Electronics Conference and Exposition

(APEC 2009), Washington, DC, USA, 15-19 February 2009; IEEE: New York, NY, USA, 2009;pp. 347-352.2.

[5]A current and future study on non-isolated DC-DC converters for photovoltaic applications, M.H. Taghvaee a,n, M.A.M.Radzi a, S.M.Moosavain b, HashimHizam a,M.Hamiruce Marhaban.

[6]A study of the basic DC-DC converters applied in maximum power point tracking. Coelho RF, et al. In: Proceedings of the power electronics conference, COBEP ’09, Brazilian; 2009. pp. 673-678.

[7]K. Agbossou, A. Bilodeau, and M.L. Doumbia 'Development of a Control Method for a Renewable Energy system with Fuel Cell, AFRICON 2009,Canada;PP.1-5.

[8]D. M. Mary Synthia Regis Prabha, kumar S.P; Devadhas G.G,: 'An Optimum Setting of Controller for a dc-dc converter Using Bacterial Intelligence Technique', ISGT India,2011,IEEE PES,PP-204-210.

[9]Liping Guo, John Y. Hung and R. M. Nelms,: 'Comparative Evaluation of Linear PID and Fuzzy Control for a Boost Converter,' IECON 2005,31ST IEEE onference publication.
[10]M.Elshaer, A. Mohamed, and O. Mohammed 'Smart Optimal Control of DC-DC Boost Converter in PV Systems',T\&D-LA,2010 IEEE/PES,PP.403-410, IEEE conference publication.

[11] H.fang and L.Chen,: 'Application of an enhanced PSO algorithm to optimal tuning of PID gains', CCDC 2009, China,PP.35-39, IEEE conference publication.

[12] Y.B.Wong,Xin Peng, Ben-Zheng Wei,: 'A new particle swarm optimization based auto-tuning of PID controller,Machine learning and cybernetics',2008,vol4,pp.1818-1823, IEEE conference publication.

[13]Chamnan Ratsame and Tanes Tanitteerapan,: 'An Efficiency Improvement Boost Converter Circuit for Photovoltaic Power System with Maximum Power Point Tracking',2011,11th ICCAS,pp.1391-1395,Oct. 26-29, 2011 in KINTEX, Gyeonggi-do, Korea.

[14]N.Mohan, T.M.Undeland, and W.P.Robbins, Powe Electroniccs: Converters, Applications and Design. New York: wiley, 1989.

[15]J. G. Kassakian, M. F. Schlecht, G. C. Verghese (1991), Principles of Power Electronics, Addison Wesley.

[16]J-H. Su, J-J. Chen, D-S.Wu(2002),: 'Learning Feedback Controller Design of Switching Converters Via MATLAB/SIMULINK', IEEE Trans. on Education, Vol.45, No.4, pp.307-315.

[17]J.C.Basilio, S.R.Matos,: 'Design of PI and PID controllers with Transients Performance Specification', IEEE Trans. Education, Vol.45, NO.4, Nov 2002.

[18]Ang, K.H., Chong, G., Li, Y.: 'PID control system analysis, design, and technology', IEEE Trans. Control Syst. Technol., 2005, 13, (4),pp. 559-576.

[19]K.J.Astrom, T.Hauglund,: 'PID controllers: Theory, Design and tuning', 2nd ed. Research Triangle Park, NC: Intrum. Soc. Amer., 1995

[20] Y. Shi and R. C. Eberhart,: 'A modified particle swarm optimizer', Proc. of IEEE Congress on Evolutionary Computation, pp. 69-73,1998.

[21] Nasri M. I, pour H. N, and Maghfoori M.,:"A PSO-Based Optimum Design of PID Controller for a Linear Brushless DC Motor' Proceedings Of World Academy Of Science, Engineering And Technology VOL. 20 April 2007.

[22] A. Balestrino*, A. Landi*, and L. Sani,: 'Performance Indices and Controller Design for Switching Converters', SPEEDAM, International Symposium on Power Electronics, Electrical Drives, Automation and Motion, 2006, IEEE

[23] Abhimanyu Kumar Yadav, Vishal Mehra, Abhijit Ray, Makarand Lokhande, "Operation of Paralleled DC-DC Converters Taking into Account Cable Resistances for Load Sharing Applications,"IJAET, Volume 6 Issue 5 , pp. 2134-2144, Nov. 2013

[24] K. Ogata, Modern Control Engineering, 3rd ed. Upper Saddle River,NJ: Prentice-Hall, 1997. 